\title{
Postoperative radiotherapy after nipple- or skin-sparing mastectomy: a review of recent institutional and pooled data
}

\author{
Jacques Bernier \\ Genolier Cancer Center, Clinique de Genolier, Genolier 1272, Switzerland
}

Correspondence to: Jacques Bernier. Email: jbernier@genolier.net

\begin{abstract}
The increasing use of nipple-sparing mastectomy (NSM) and skin-sparing mastectomy (SSM) in the treatment of nonmetastatic breast cancer is justified by considerations linked to their therapeutic index. In selected patients, efficacy results tend to be similar to those observed after radical modified mastectomy and at the same time, subcutaneous mastectomies preserve the patient's body image. Yet the oncologic safety of the two former surgical approaches is still a matter of debate, also in consideration of the almost complete absence of clinical studies directed to prospective, controlled comparisons between subcutaneous and radical modified mastectomies. In addition, no clear statement-and consequently no consensus-emerges from the rather rare reports addressing the issue of whether or not there exist robust algorithms for guiding decision-making in delivering postoperative radiotherapy after NSM or SSM. The objective of the present review article is to revisit the dataset recently provided by the literature, which might help oncology teams optimise local treatment in this patient population.
\end{abstract}

Keywords: breast cancer, skin-sparing mastectomy, nipple-sparing mastectomy, modified radical mastectomy, postoperative radiotherapy, treatment outcome, late complications

Published: 11/05/2018

Received: $23 / 02 / 2018$

ecancer 2018, 12:834 https://doi.org/10.3332/ecancer.2018.834

Copyright: (c) the authors; licensee ecancermedicalscience. This is an Open Access article distributed under the terms of the Creative Commons Attribution License (http://creativecommons.org/licenses/by/3.0), which permits unrestricted use, distribution, and reproduction in any medium, provided the original work is properly cited. 


\section{Introduction}

Throughout the past two decades, both nipple-sparing mastectomy (NSM) and skin-sparing mastectomy (SSM) have been gaining ground in the surgical management of nonmetastatic breast cancer patients. The main reason for this trend relates to the therapeutic index elicited for NSM and SSM, which was shown to compare favourably with that observed for modified radical mastectomy (MRM). Indeed, the literature suggests that treatment outcomes of NSM, SSM and MRM tend to be similar as regards efficacy endpoints, and at the same time, patients draw a number of advantages from the two former surgical modalities, especially in terms of organ and body image preservation $[1,2-9]$.

Whether to deliver postoperative radiotherapy (PORT) after NSM or SSM or not is nowadays an issue essentially addressed by multidisciplinary tumour boards involving not only surgeons and radio-oncologists but also diagnosticians, pathologists and medical oncologists. Often, such a decision-making process turns out to be a challenging task, for no straightforward, prospective comparison between subcutaneous radical mastectomies and MRMs has emerged so far from reports analysing the exact relevance of PORT after NSM and SSM $[10,11]$.

The objective of this review article is to revisit the messages recently provided by the literature which might help oncology teams optimise local treatment in this patient population.

\section{Methods}

We used search strings on studies addressing the issue of interaction between NSM and SSM and adjuvant radiotherapy, via the following search terms: breast cancer, SSM, NSM, MRM, PORT, treatment outcome and late complications. This review article is essentially based on full articles published since 2000 and retrieved from the PubMed search engine (http://www.ncbi.nlm.nih.gov/pubmed).

\section{Results}

In general, recent reports do not provide any clear statement on the indication of PORT after NSM or SSM. Nevertheless, we can identify, in the recent literature, a number of datasets retrieved from institutional reports, pooled analyses, and an international survey of practices.

\section{Institutional reports: risks of recurrences after SSM or NSM}

In comparison with MRM, NSM and SSM may leave mammary gland in subcutaneous tissues. This observation is corroborated by two datasets, Torresan et al [12] reported in 2005. First, residual mammary tissue was still present in about $60 \%$ of the surgical specimens from a cohort of 42 patients presenting with stage 0-III disease. Second, there was a direct correlation between the presence of residual breast tissue and skin flap thickness: when it exceeded $5 \mathrm{~mm}$, tumour cells are identified in up to $9.5 \%$ of the surgical specimens.

Likewise the involvement of the nipple-areolar complex (NAC) by tumour microfoci was demonstrated by Cense et al [13] in nearly $60 \%$ of mastectomy samples. The main features related to a higher risk of NAC involvement by tumour are a small distance between the NAC and tumour $(<4-5 \mathrm{~cm})$, positive lymph nodes, central tumour location and multicentricity [14]. Nevertheless, local regional relapse rates after NSM are low in patients with early-stage breast cancer [15].

The persistence of mammary tissue after SSM or NSM obviously increases the risk of local failure if tumour cells are present in this residual tissue [16-19]. In this, the more advanced the local disease, the higher the risk of local recurrence. In a retrospective study by Meretoja et al [20], the local regional failure rates with a mean follow-up of 70 months were 31 and $5.8 \%$ in patients with stage III and stage 0 -II, respectively. 
After SSM, the most significant risk factors for local recurrence identified in two studies are nodal involvement, tumour size, poorly differentiated carcinomas, and lympho-vascular invasion (LVI) [5, 21]. In other three studies, clinical factors such as tumour size of $4 \mathrm{~cm}$ or more, $[15,22,23]$ chest wall infiltration [22], and any positive lymph node or $>3$ positive lymph nodes [15, 22] were significantly linked to higher risk of local regional relapse.

\section{Institutional reports: impact of PORT on complication rates}

In 2007, Meretoja published a report on a cohort of 207 consecutive women who underwent, from 1992 to 2001 , SSM and immediate breast reconstruction immediate breast reconstruction (IBR) without any adjuvant radiotherapy [20]. This Finnish study found that with a mean follow-up of 70 months, late complications included native skin flap necrosis (10\%), hematoma (10\%), infection (3.5\%), anastomotic thrombosis $(5 \%)$ and hernia (3\%).

It has been repeatedly substantiated that PORT delivered to reconstructed breast carries a higher risk of complications compared to that of no PORT [24-26]. Before the turn of the century, Hunt et al [16] showed that patients treated with immediate, autologous TRAM reconstructions develop fat necrosis and radiation fibrosis in $16 \%$ and $11 \%$ of cases, respectively. Another study, comparing 39 irradiated implant reconstructed breasts with 338 nonirradiated reconstructions, elicited a higher incidence of capsular contracture in the irradiated group [19].

In a recent report published in 2015, Tang et al [27] analysed treatment outcomes in a large population of 982 patients treated from 2007 to 2013 with NSM plus immediate reconstruction [27]. Compared to breasts with no radiotherapy, PORT increased overall complications (10.2 versus $17.5 \%, P=0.03)$, nipple loss $(0.9$ versus $4.1 \%, \mathrm{P}=0.02$,), and rates of reconstruction failure $(2.2$ versus $8.2 \%, P=0.003)$. On multivariate regression analysis, PORT (OR, 2.29, $P=0.015)$, age $>55$ years $(\mathrm{OR}, 2.03, P=0.04)$, breast volume $\geq 800 \mathrm{~cm} 3(\mathrm{OR}, 1.96$, $P=0.04)$, smoking (OR, 2.62, $P=0.001)$, and peri-areolar incision $(\mathrm{OR}, 1.74, P=0.03)$ were independent risk factors for complications. The authors concluded that despite higher complication rates after PORT, reconstruction failure and nipple/areola necrosis remained infrequent. Moreover, capsule formation can readily be treated with capsulotomy or capsulectomy [28].

\section{Pooled analysis: the nipple skin-sparing mastectomy model}

Out of 17 studies analysed by Janssen et al [29] in 2015, only seven provided a detailed description of the radiotherapy modalities. In most studies, the delivered dose was 50 Gy. Radiotherapy indications varied markedly among the institutions. Boneti et al [22] and Burdge et al [30] delivered this level of dose to the thoracic wall in patients with for tumours $>5 \mathrm{~cm}$ and/or $\geq 4$ positive axillary nodes. Moyer et al [31] delivered PORT when resection margins were $\leq 1 \mathrm{~mm}$. In another study by Rulli et al [32], PORT was delivered only in patients for whom residual mammary tissue had been detected. A significant difference in treatment outcome was found in only one study in a cohort of 216 patients, comparing PORT versus no PORT groups, with local regional failure rate of $8.5 \%$ and $28.4 \%$, respectively [23]. The unexpectedly high failure rate observed in the no PORT group is bound to be linked to the inclusion of high-risk patients in this study. Indeed tumours $>3$ $\mathrm{cm}$ were included in the analysis, and $40 \%$ of cases were node-positive.

At the European Institute of Oncology in Milan, Petit et al [33] performed radiotherapy (RT) exclusively to the NAC as either electron intraoperative radiotherapy or as a single dose of $16 \mathrm{~Gy}$ (electron beams) a few days after surgery. The study reported a rate of local regional recurrence of $1.4 \%$, with all recurrences distant from the NAC. Treatment outcomes were not significantly different between the patients receiving ELIOT $(n=800)$ and those receiving delayed PORT $(n=201)$, on 5 days per week [30, 32, 34].

\section{International survey of practices}

Finally, an international survey, conducted by Marta et al [35], collected data from 550 physicians (298 radio-oncologists and 252 breast surgeons), mostly practicing in South America (42\%), North America, (30\%) and Europe (26\%). NSM and SSM were performed in more than $15 \%$ of newly diagnosed breast cancer patients, by about $30 \%$ of the respondents. 
Answers to the questionnaire resulted in the identification of nine risk factors, practitioners include into the decision to deliver PORT or not after NSM/SSM and IBR. These factors were: 1) nodal involvement; 2) LVI; 3) grade III carcinomas; 4) triple negative histo-type; 5) young age; 6) positive surgical margins; 7) tumour size; 8) extracapsular extension (ECE) and 9) multi-centric presentation. As expected, radiooncologists and surgeons did not fully agree on the magnitude of the risk level affecting each of these factors. For instance, the answers from the two professional disciplines most significantly diverged for the first five factors reported here above (with $p<0.001$ for each of them).

Importantly enough, there was no consensus between surgeons and radio-oncologists with respect to both how to define residual breast tissue after NSM/SSM and the need to assess the presence of residual breast tissue after surgery. In terms of cut-off values for the risk factors, there were also differences in appreciation between the two disciplines: while most radio-oncologists and surgeons tended to consider age below 40 years and tumour exceeding $5 \mathrm{~cm}$ in diameter as reasonable cut-offs, there was no full agreement as regards the number of involved nodes: radio-oncologists put the cut-off at one lymph node, surgeons at more than three.

\section{Discussion}

So far, there has been no controlled clinical study that assessed prospectively who will benefit from PORT after NSM or SSM, and who will not. The only messages we can retrieve from recent publications are there based on retrospective analyses of cohorts of patients.

The relevance of historical comparisons is particularly questionable in a surgical field such as subcutaneous mastectomy, especially in consideration of high inter-study heterogeneities in surgical techniques and selection criteria to identify patients amenable to NSM/SSM, with or without PORT.

In a recent analysis of the current role of PORT after NSM, a total of 112,817 patients were isolated from the SEER database [36]. Over the 2006-2010 period, NSM and nonNSM procedures were performed in $470(0.4 \%)$ and $112,347(99.6 \%)$ cases. Patients with 0 nodes/size $\leq 2 \mathrm{~cm}, 0$ nodes/size $2-5 \mathrm{~cm}$, and unexamined axilla/size $\leq 2 \mathrm{~cm}$ had higher odds of PORT when compared with size- and node-matched mastectomy patients. Multivariate logistic regression showed that NSM patients had higher odds of radiation $(\mathrm{OR}, 2.01, P<0.001)$ than mastectomy patients.

Up until recently, the European Institute of Oncology in Milan recommended the use of intraoperative RT to the NAC in this latter patient population [37]. In patients treated with NSM, Petit et al [38] indeed showed, in 2012, that risks of recurrences in the breast included high grade tumours, overexpression/amplification of HER2/neu and molecular subtype luminal B. In the nipple areola complex, the corresponding risk factors were age $<45$ years, absence of oestrogen receptors, high grade tumours, and HER2/neu overexpression and high Ki-67.

Retrospective studies on NAC indicate that $10 \%$ to $30 \%$ of cases receive PORT [23, 30, 31, 37, 39-46].They also show large variations in treatment outcomes: local regional recurrence rates vary from $0 \%$ to $10 \%$, and failures in the NAC are observed in $0 \%$ to $3 \%$ of cases. NAC necrosis is reported in $0 \%$ to $37 \%$ of patients benefiting from NSM.

There is also a grey zone in the literature as regards the specific impact of nodal status on treatment outcome after NSM or SSM. It is therefore legitimate to take into consideration the data retrieved from the Early Breast Cancer Trialists' Collaborative Group's meta-analysis [47]. Compared to no adjuvant radiotherapy, PORT delivered after MRM and axillary dissection was found to decrease significantly local regional recurrence rates, whatever the number of positive nodes. This large-scale analysis strongly suggests that all node-positive breast cancer patients treated with SSM or NSM should actually receive PORT.

In the present state of knowledge, the current review strongly suggests that the recommendations by Marta et al [35] are in agreement with the messages drawn from both institutional and pooled analyses: following SSM and NSM, PORT has to be delivered to patients with tumour size $>5 \mathrm{~cm}$, positive node(s), positive surgical margins or triple negative histo-types. It is also generally accepted that PORT is indicated in patients with thick skin flaps $>5 \mathrm{~mm}$, or skin flaps $<5 \mathrm{~mm}$ with high risk factors such as age $<50$ years, nodal ECE, lympho-vascular space invasion or multi-centric tumours. Interestingly enough the findings on flap thickness strongly suggest to measure it using magnetic resonance imaging, in order to predict the presence of residual breast tissue status after NSM and SSM. 
Finally, this review confirms that, despite the fact that an increase in complications is documented in patients receiving PORT, immediate breast reconstruction using tissue expansion and implant is an acceptable option for women undergoing NSM and SSM for breast cancer [3].

\section{Conclusions}

Whether SSM or NSM is safe in patients to whom no PORT is delivered remains a matter of controversy, especially in the absence of direct, controlled comparisons between patients with or without adjuvant radiotherapy. The literature on PORT after NSM and SSM continues to elicit rather large inconsistencies when treatment efficacy is the main endpoint. In particular, NSM, which spares a small amount of glandular tissue to protect the areola blood supply, raises concerns about the oncologic safety of this type of surgery, especially in high-risk patients. PORT is likely to reduce the risk of local failure in patients treated with subcutaneous mastectomy. Although some reasonable recommendations emerge from large-scale pooled analyses or surveys, the absence of prospective studies still prevents surgeons and radio-oncologists to identify those cases that are bound to draw a clear benefit from PORT after SSM or NSM. This definitely warrants the activation of randomised trials in these clinical settings.

\section{Conflicts of interest and funding statement}

The author has no conflicts of interest and did not receive any funding to publish this review article.

\section{References}

1. Tokin C, Weiss A, and Wang-Rodriguez J, et al (2012) Oncologic safety of skin-sparing and nipple-sparing mastectomy: a discussion and review of the literature Int $J$ Surg Oncol 921821

2. Newman LA, Kuerer HM, and Hunt KK, et al (1998) Presentation, treatment, and outcome of local recurrence after skin-sparing mastectomy and immediate breast reconstruction Ann Surg Oncol 5 620-626 https://doi.org/10.1007/BF02303832 PMID: 9831111

3. Greenway RM, Schlossberg L, and Dooley WC (2005) Fifteen-year series of skin-sparing mastectomy for stage 0 to 2 breast cancer Am J Surg 190 918-922 https://doi.org/10.1016/j.amjsurg.2005.08.035 PMID: 16307946

4. Lim W, Ko BS, and Kim HJ, et al (2010) Oncological safety of skin sparing mastectomy followed by immediate reconstruction for locally advanced breast cancer J Surg Oncol 102 39-42 https://doi.org/10.1002/jso.21573 PMID: 20578076

5. Medina-Franco H, Vasconez LO, and Fix RJ, et al (2002) Factors associated with local recurrence after skin sparing mastectomy and immediate breast reconstruction for invasive breast cancer Ann Surg 235 814-819 https://doi.org/10.1097/00000658200206000-00008 PMID: 12035037 PMCID: 1422510

6. Reefy S, Patani N, and Anderson A, et al (2010) Oncological outcome and patient satisfaction with skin-sparing mastectomy and immediate breast reconstruction: a prospective observational study BMC cancer 10 171 https://doi.org/10.1186/1471-240710-171 PMID: 20429922 PMCID: 2873394

7. Piper M, Peled AW, and Foster RD, et al (2013) Total skinsparing mastectomy: a systematic review of oncologic outcomes and Postoperative Complications Ann Plast Surg 70(4) 435-437 https://doi.org/10.1097/SAP.0b013e31827e5333 PMID: 23486127

8. Lanitis S, Tekkis PP, and Sgourakis G, et al (2010) Comparison of skin-sparing mastectomy versus non-skin-sparing mastectomy for breast cancer: a meta-analysis of observational studies Ann Surg 251 632-639 https://doi.org/10.1097/SLA.0b013e3181d35bf8 PMID: 20224371

9. Yi M, Kronowitz SJ, and Meric-Bernstam F, et al (2011) Local, regional, and systemic recurrence rates in patients undergoing skin-sparing mastectomy compared with conventional mastectomy Cancer 117 916-924 https://doi.org/10.1002/cncr.25505

10. Ananthakrishnan P and Feldman S (2012) Nipple-sparing mastectomy: indications, oncologic safety Minerva Chir 67 257-270 PMID: 22691830 
11. Orecchia $\mathrm{R}$ (2016) The use of postoperative radiation after nipple sparing mastectomy Gland Surg 5(1) 63-68 PMID: 26855910 PMCID: 4716864

12. Torresan RZ, dos Santos CC, and Okamura H, et al (2005) Evaluation of residual glandular tissue after skin-sparing mastectomies Ann Surg Oncol 12 1037-1044 https://doi.org/10.1245/ASO.2005.11.027 PMID: 16244800

13. Cense HA, Rutgers EJ, and Lopes Cardozo M, et al (2001) Nipple-sparing mastectomy in breast cancer: a viable option? Eur J Surg Oncol 27 521-526 https://doi.org/10.1053/ejso.2001.1130 PMID: 11520082

14. Laronga C, Kemp B, and Johnston D, et al (1999) The incidence of occult nipple-areola complex involvement in breast cancer patients receiving a skin-sparing mastectomy Ann Surg Oncol 6 609-613 https://doi.org/10.1007/s10434-999-0609-z PMID: 10493632

15. Niemeyer M, Paepke S, and Schmid R, et al (2011) Extended indications for nipple-sparing mastectomy Breast J 17 296-299 https://doi.org/10.1111/j.1524-4741.2011.01079.x PMID: $\underline{21450018}$

16. Hunt KK, Baldwin BJ, and Strom EA, et al (1997) Feasibility of postmastectomy radiation therapy after TRAM flap breast reconstruction Ann Surg Oncol 4 377-384 https://doi.org/10.1007/BF02305549 PMID: 9259963

17. Sotheran WJ and Rainsbury RM (2004) Skin-sparing mastectomy in the UK: a review of current practice Ann R Coll Surg Eng/ 86 82-86 https://doi.org/10.1308/003588404322827437 PMID: 15005923 PMCID: 1964147

18. Cao D, Tsangaris TN, and Kouprina N, et al (2008) The superficial margin of the skin-sparing mastectomy for breast carcinoma: factors predicting involvement and efficacy of additional margin sampling Ann Surg Oncol 15 1330-1340 https://doi. org/10.1245/s10434-007-9795-8 PMID: 18246402 PMCID: 2958107

19. Sheikh F, Rebecca A, and Pockaj B, et al (2011) Inadequate margins of excision when undergoing mastectomy for breast cancer: which patients are at risk? Ann Surg Oncol 18 952-956 https://doi.org/10.1245/s10434-010-1406-4

20. Meretoja TJ, Rasia S, and von Smitten KA, et al (2007) Late results of skin-sparing mastectomy followed by immediate breast reconstruction Br J Surg 94 1220-1225 https://doi.org/10.1002/bjs.5815 PMID: 17579346

21. Carlson GW, Styblo TM, and Lyles RH, et al (2003) Local recurrence after skin-sparing mastectomy: tumor biology or surgical conservatism? Ann Surg Oncol 10 108-112 https://doi.org/10.1245/ASO.2003.03.053 PMID: 12620903

22. Boneti C, Yuen J, and Santiago C, et al (2011) Oncologic safety of nipple skin-sparing or total skin-sparing mastectomies with immediate reconstruction J Am Coll Surg 212 686-693 https://doi.org/10.1016/j.jamcollsurg.2010.12.039 PMID: 21463813

23. Benediktsson KP and Perbeck $L$ (2008) Survival in breast cancer after nipplesparing subcutaneous mastectomy and immediate reconstruction with implants: a prospective trial with 13 years median follow-up in 216 patients Eur J Surg Oncol 34 143-148 https://doi.org/10.1016/j.ejso.2007.06.010

24. Toth BA and Lappert $P$ (1991) Modified skin incisions for mastectomy: the need for plastic surgical input in preoperative planning Plastic Reconstr Surg 87 1048-1053 https://doi.org/10.1097/00006534-199106000-00006

25. Carlson GW (1996) Skin sparing mastectomy: anatomic and technical considerations Am Surg 62 151-155 PMID: $\underline{8554192}$

26. Uriburu JL, Vuoto HD, and Cogorno L, et al (2006) Local recurrence of breast cancer after skin-sparing mastectomy following core needle biopsy: case reports and review of the literature Breast J 12 194-198 https://doi.org/10.1111/j.1075-122X.2006.00240.X PMID: 16684314

27. Tang R, Coopey SB, and Colwell AS, et al (2015) Nipple-sparing mastectomy in irradiated breasts: selecting patients to minimize complications Ann Surg Oncol 22 3331-3337 https://doi.org/10.1245/s10434-015-4669-y PMID: 26202557 
28. Headon H, Kasem A, and Mokbel K (2015) Capsular contracture after breast augmentation: an update for clinical practice Arch Plast Surg 42(5) 532-543 https://doi.org/10.5999/aps.2015.42.5.532 PMID: 26430623 PMCID: 4579163

29. Janssen S, Holz-Sapra E, and Rades D, et al (2015) Nipple-sparing mastectomy in breast cancer patients: The role of adjuvant radiotherapy Oncol Lett 9(6) 2435-2441 https://doi.org/10.3892/ol.2015.3084 PMID: 26137086 PMCID: 4473656

30. Burdge EC, Yuen J, and Hardee M, et al (2013) Nipple skin-sparing mastectomy is feasible for advanced disease Ann Surg Oncol 20 3294-3302 https://doi.org/10.1245/s10434-013-3174-4 PMID: 23975304

31. Moyer HR, Ghazi B, and Daniel JR, et al (2012) Nipple-sparing mastectomy: Technical aspects and aesthetic outcomes Ann Plast Surg 68 446-450 https://doi.org/10.1097/SAP.0b013e3182394bba PMID: 22531398

32. Rulli A, Caracappa D, and Barberini F, et al (2013) Oncologic reliability of nipple-sparing mastectomy for selected patients with breast cancer In Vivo 27 387-394 PMID: 23606696

33. Petit JY, Veronesi U, and Orecchia R, et al (2003) The nipple-sparing mastectomy: Early results of a feasibility study of a new application of perioperative radiotherapy (ELIOT) in the treatment of breast cancer when mastectomy is indicated Tumori 89 288-291 https://doi.org/10.1177/030089160308900311 PMID: 12908785

34. Petit JY, Veronesi U, and Orecchia R, et al (2009) Nipple sparing mastectomy with nipple areola intraoperative radio- therapy: One thousand and one cases of a five years experience at the European institute of oncology of Milan (EIO) Breast Cancer Res Treat 117 333-338 https://doi.org/10.1007/s10549-008-0304-y PMID: 19152026

35. Marta GN, Poortmans P, and de Barros AC, et al (2017) Multidisciplinary international survey of post-operative radiation therapy practices after nipple-sparing or skin-sparing mastectomy Eur J Surg Oncol 43(11) 2036-2043 https://doi.org/10.1016/j. ejso.2017.09.014 PMID: 28967564

36. Crowe JP, Patrick RJ, and Yetman RJ, et al (2008) Nipple-sparing mastectomy update: One hundred forty-nine procedures and clinical outcomes Arch Surg 143 1106-1110 https://doi.org/10.1001/archsurg.143.11.1106 PMID: 19015470

37. Petit JY, Veronesi U, and Rey P, et al (2009) Nipple-sparing mastectomy: risk of nipple-areolar recurrences in a series of $\mathbf{5 7 9}$ cases Breast cancer Res Treat 114 97-101 https://doi.org/10.1007/s10549-008-9968-6

38. Petit JY, Veronesi U, and Orecchia R, et al (2012) Risk factors associated with recurrence after nipple-sparing mastectomy for invasive and intraepithelial neoplasia Ann Oncol 23 2053-2058 https://doi.org/10.1093/annonc/mdr566 PMID: 22231025

39. Gerber B, Krause A, and Dieterich M, et al (2009) The oncological safety of skin sparing mastectomy with conservation of the nipple-areola complex and autologous reconstruction: an extended follow-up study Ann Surg 249(3) 461-468 https://doi. org/10.1097/SLA.0b013e31819a044f PMID: 19247035

40. Sakamoto N, Fukuma E, and Higa K, et al (2010) Early results of an endoscopic nipple-sparing mastectomy for breast cancer Indian J Surg Oncol 1(3) 232-239 https://doi.org/10.1007/s13193-011-0057-7 PMID: 22695768 PMCID: 3372951

41. Harness JK, Vetter TS, and Salibian AH (2011) Areola and nipple-areola-sparing mastectomy for breast cancer treatment and risk reduction: report of an initial experience in a community hospital setting Ann Surg Oncol 18(4) 917-922 https://doi. org/10.1245/s10434-010-1365-9 PMID: 21308484 PMCID: 3052454

42. Shi A, Wu D, and Li X, et al (2012) Subcutaneous Nipple-Sparing Mastectomy and Immediate Breast Reconstruction Breast Care (Basel) 7(2) 131-136 https://doi.org/10.1159/000337640

43. Warren Peled A, Foster RD, and Stover AC, et al (2012) Outcomes after total skin-sparing mastectomy and immediate reconstruction in 657 breasts Ann Surg Oncol 19(11) 3402-3409 https://doi.org/10.1245/s10434-012-2362-y PMID: 22526909 
44. Fortunato L, Loreti $A$, and Andrich $R$, et al (2013) When mastectomy is needed: is the nipple-sparing procedure a new standard with very few contraindications? J Surg Oncol 108(4) 207-212 https://doi.org/10.1002/jso.23390 PMID: 23913775

45. Sbitany H, Wang F, and Peled AW, et al (2014) Immediate implant-based breast reconstruction following total skin-sparing mastectomy: defining the risk of preoperative and postoperative radiation therapy for surgical outcomes Plast Reconstr Surg 134(3) 396-404 https://doi.org/10.1097/PRS.0000000000000466 PMID: 25158699

46. Reish RG, Lin A, and Phillips NA, et al (2015) Breast reconstruction outcomes after nipple-sparing mastectomy and radiation therapy Plast Reconstr Surg 135(4) 959-966 https://doi.org/10.1097/PRS.0000000000001129 PMID: 25811561

47. EBCTCG (Early Breast Cancer Trialists' Collaborative Group), McGale P, and Taylor C, et al (2014) Effect of radiotherapy after mastectomy and axillary surgery on 10-year recurrence and 20-year breast cancer mortality: metaanalysis of individual patient data for $\mathbf{8 1 3 5}$ women in 22 randomised trials Lancet 383 2127-2135 https://doi.org/10.1016/S0140-6736(14)60488-8 PMID: 24656685 PMCID: $\underline{5015598}$ 